\title{
SUCCESS FACTORS FOR MICRO AND SMALL AGRIBUSINESS ENTERPRISES (MSES) - THE CASE OF GHANA*
}

\author{
Alfred Asuming Boakye ${ }^{1 凶}$, Richard Ampadu-Ameyaw ${ }^{2}$, George Owusu Essegbey ${ }^{2}$, \\ Justina Adwoa Onumah ${ }^{2}$ \\ ${ }^{1}$ University of Ghana, Ghana \\ ${ }^{2}$ Science and Technology Policy Research Institute, CSIR, Ghana
}

\begin{abstract}
Micro and Small Enterprises (MSEs) are considered to be engines of economic growth worldwide. Their efficiency and competitiveness is critical to the creation of employment, income generation and poverty reduction and thereby to general growth of the economy. However, studies on MSEs in Ghana have mainly focused on the financial performance with little or no attention paid to the contribution of environmental and socio-demographic factors to entrepreneurial success. The data for this study was obtained from Micro and Small Enterprises (MSEs) in some twenty districts across Ghana. A total of 2899 entrepreneurs were interviewed. A binary logit regression was used in determining the impact of socio-demographic and environmental factors on entrepreneurial business success. As shown by the results, the odds of business success increase by $67 \%$ if the formal education period is extended by one year. Supportive environmental factors also significantly contribute to business success. This study recommends a policy that will help improving access to market for MSEs. Policy makers should consider strengthening the potential of institutional support in terms of market information delivered by public institutions to enhance the business success of agribusiness entrepreneurs in Ghana.
\end{abstract}

Keywords: entrepreneurship; business success; Micro and Small Enterprises (MSEs)

\section{INTRODUCTION}

The Ghanaian economy is replete with Micro and Small Enterprises (MSEs) across the major sectors (agriculture, services and industry). In Ghana, these enterprises make up the bulk of the informal sector and are considered to be the engines of economic growth. Statistics indicate that about $70 \%$ of Ghanaian enterprises are micro- to small-sized operators who significantly contribute to the GDP (about 70\%) and account for about $92 \%$ of businesses in Ghana (Villars, 2004). MSEs are useful in ensuring income stability, growth and employment. The National Board for Small Scale Enterprises (NBSSI, the regulatory body for micro, small and medium enterprises in Ghana) estimates that MSMEs constitute about $90 \%$ of the private sector's contribution to the GDP (Hayford, 2012). Their efficiency and competitiveness is critical to the country's economic growth, creation of employment and poverty reduction. According to Kayanula and Quartey (2000), the importance of Micro and Small Scale Enterprises (MSEs) in Ghana is primarily manifested by their smooth adaptability to customer requirements; their ability to absorb funds from

*Funding for this study was provided by the International Fund for Agricultural Development (IFAD) through the Rural Enterprises Program (REP) of the Government of Ghana.

$\bowtie$ MPhil Alfred Asuming Boakye, Forest and Horticultural Crops Research, School of Agriculture, College of Basic and Applied

Sciences, University of Ghana, Ghana, e-mail: aasumingboakye@ug.edu.gh 
financial institutions which otherwise would have been idle; the labor-intensiveness of their operation (as they employ more labor per unit of capital than large enterprises); their broad use of local resources (which means less foreign exchange requirements); and especially by their use and promotion of indigenous technological know-how. MSEs are also widely dispersed throughout the country. This, combined with their labor intensity, is a reason to believe that MSEs' production units can promote a more equitable distribution of wealth than large companies. In the context of this paper, the authors adopt the working definition provided by the Regional Project on Enterprise Development Ghana, which classifies micro enterprises as those with less than 5 employees; and small enterprises as those employing 5 to 29 employees.

\section{RESEARCH PROBLEM}

In spite of their significant contribution to Ghana's general economic development, MSEs face major challenges, including difficulty in accessing capital for investment purposes, poor working conditions, low technology levels, low quality products, inadequate networking, poor distribution system, poor regulatory system, inadequate managerial support, poor infrastructural facilities and inadequate market information (Aryeetey et al., 1994; Kayanula and Quartey, 2000). These challenges ultimately prevent MSE owners from realizing their full potential as entrepreneurs, so they could make a valuable contribution to society. In the face of these challenges, a glaring concern that emerges relates to the drivers of the owners' business success. The success of MSEs is considerably variable, and the key underlying factors relate to the characteristics of entrepreneurs, finance, capitalization, marketing, technology, social network, gender, government policy issues (support and creation of the enabling environment), and enterprise management. This takes a great deal of investigation. Most studies on MSEs in Ghana have focused on their financial performance while those linking environmental and demographic factors to entrepreneurial success have received little or no attention. It is therefore of utmost importance to investigate factors that are likely to determine the success or failure of MSEs in Ghana, especially those related to both the demographic characteristics of entrepreneurs and the economic environment. This study provides a platform that can help the entrepreneurs identify the factors behind their business success, thereby reducing the risk of failure and increasing the chances of success.

Research questions that need to be answered as a part of the above research problem border on socio-demographic issues and motivation for starting businesses and their relation to business success; and the environmental factors that have any effect on entrepreneurial business success.

Two objectives specifically address the questions raised. These are (1) to identify the relationship between socio-demographic factors and motivation for starting business, on one side, and the success of agribusiness MSEs in Ghana, on the other; and (2) to determine the effect of socio-demographic and environmental factors on the success of MSEs in the Ghanaian agribusiness sector.

\section{CONCEPTUAL FRAMEWORK}

The decisions and capabilities of an entrepreneur ultimately influence the failure or success of an MSE. Nonetheless, firms do not operate in isolation but are closely linked with the macroeconomic, political, and social environment (Chowdhury et al., 2013). Education and experience in a particular business area are considered to be the key factors of business success (Wanigasekara and Surangi, 2010), as confirmed by the results obtained by Chowdhury et al. (2013). They indicate that experience and education exhibit positive correlation with, and have a direct impact on, entrepreneurial business success. However, there is contention regarding the influence of age on business success. While some authors argue that age positively affects entrepreneurial business success, other results disprove these findings. For example, Nimoh et al. (2011) claim that age has no influence on entrepreneurial performance while Chowdhury et al. (2013) argue that it adversely affects entrepreneurial business success. Numerous studies (Hisrich, 1990; Lussiers and Pfeifer, 2001; Raman, 2004) found the importance of the entrepreneur's experience to be critical to business success. Again, environmental factors such as institutional support from government agencies, access to market information, improved technology, etc. have also been linked to entrepreneurial business success (Larsen and Lewis, 2007; McDowell, 1997; Mintoo, 2006). According to Mead and Liedholm (1998), lack of access to market, information, finance and institutional support are major factors that hamper 


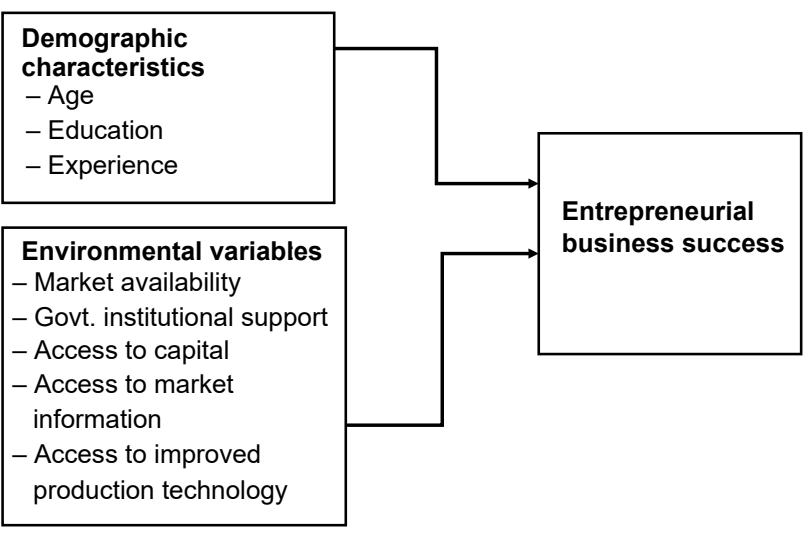

Fig. 1. Conceptual framework of factors behind entrepreneurial business success

Source: own elaboration.

the success of MSE entrepreneurs. Thus, if available, these factors become drivers of entrepreneurial success. The above discussion reveals that business success depends on both demographic and environmental factors. Figure 1 reveals the connection between these factors and entrepreneurial business success. This study was based on the conceptual framework as depicted below:

\section{RESEARCH METHODOLOGY}

\section{Sampling procedure and size}

The data for this study was obtained from a Business Opportunity Identification Survey (BOIS) conducted by the Science and Technology Policy Research Institute (STEPRI) of the Council for Scientific and Industrial Research (CSIR) of the Ghana for the Rural Enterprises Program.

The sample size was estimated using the Slovin's formula for sample size estimation, as specified below:

where:

$$
n=\frac{N}{\left(1+N e^{2}\right)}
$$

$n=$ sample size

$N=$ Total population

$e=$ margin of error

With a margin of error $e$ of 0.01 (which denotes the acceptable probability of error in sample selection) and an estimated number of 9,925 Micro and Small Enterprises (MSEs) in some twenty districts across Ghana, a total of 4,981 entrepreneurs in informal MSEs were surveyed. Out of this number, 2899 enterprises (representing about $58.20 \%$ of the total number) were agribusinesses active in traditional forms of agricultural production and marketing; that group was used in the analysis. They include manufacturers of simple agricultural implements, agro-processing businesses, street food vendors and restaurants, as well as providers of pre- and post-harvest services like tractor services, sorting, packaging etc.

\section{Data analysis}

Based on a literature review, the following hypotheses are tested to achieve the first objective:

$\mathrm{H}_{1}$ : There is no significant relationship between the age of entrepreneurs and business success.

$\mathrm{H}_{2}$ : There is no significant relationship between education of the entrepreneurs and their success.

$\mathrm{H}_{3}$ : There is no significant relationship between work experience of the entrepreneurs and their success.

The chi-squared test was used to measure the relationship between the socio-demographic characteristics of entrepreneurs and their business success.

To achieve the second objective, this study used the logistic regression in order to identify the factors that affect entrepreneurial success. That method was employed because the dependent variable is a binary outcome of whether the entrepreneur is successful or not.

The model was as follows:

$$
\log \left[\frac{p}{(1-p)}\right]=\beta_{0}+\beta_{1 \ldots n} x+\mu
$$

where:

$\log \left[\frac{p}{(1-p)}\right]=$ dependent variable (binary outcome)

$x=$ independent variables which may have an effect on the dependent variable

$\beta_{1 \ldots n}=$ coefficients of the independent variables which are to be determined

$\mu=$ error term of the function

\section{Measurement of the dependent variable}

A series of questions were asked regarding drivers of entrepreneurial business success. Because the questions boil down to the entrepreneurs' subjective perceptions of success, their replies served as the dependent variable. The subjective perceptions of entrepreneurs in assessing their business success were also grounded in 
literature. Although several studies have relied on different performance measures (mainly for large companies), a major indicator widely used to determine business success in small companies consists in collecting subjective feedback from the entrepreneurs. This is usually based on the entrepreneur's satisfaction with a set of goals assumed to be a determinant of business success. For example, Chowdhury et al., 2013; Luk, 1996; Perez and Canino, 2009 all used subjective perceptions of entrepreneurs (based on the Likert scale) to determine their business success.

However, this study adopted a slightly different approach, questioning the entrepreneurs on a number of issues to subjectively assess their business success. The most important questions included the following: (1) Are you able to meet your maximum production or processing level as a proxy for business success? This question was important because most entrepreneurs find it crucial to make full use of their production capacity which is reflected by their ability to meet defined production or processing targets. Therefore, if the agribusinesses are able to reach their desired maximum production level, they are considered successful. (2) Are you able to sell all your products regularly? This was a good predictor for business success because it serves as a motivation to work at maximum production capacity. Also, the ability to maximize production contributes to business success since the primary objective of an entrepreneur operating at full capacity is to readily market its production. (3) How do you assess the growth of your business over

Table 1. Definition of variables and a priori expectations

\begin{tabular}{|c|c|c|}
\hline Variable & Description & $\begin{array}{l}\text { a priori } \\
\text { expectations }\end{array}$ \\
\hline $\mathrm{AGE}_{1}$ & age of the entrepreneur (continuous variable) & $+/-$ \\
\hline $\mathrm{EDUC}_{2}$ & years of formal education (continuous variable) & + \\
\hline $\mathrm{EXP}_{3}$ & years of business experience (continuous variable) & + \\
\hline $\mathrm{CSIR}_{4}$ & support from CSIR (dummy variable: $1=$ Yes, $0=$ No) & + \\
\hline $\mathrm{BAC}_{5}$ & support from the business advisory centre of NBSSI (dummy variable: $1=$ Yes, $0=$ No) & + \\
\hline GRATIS $_{6}$ & support from the GRATIS foundation (dummy variable: $1=$ Yes, $0=$ No) & + \\
\hline SUPPINPUTS $_{7}$ & support from input dealers (raw materials, seeds etc.) (dummy variable: $1=$ Yes, $0=$ No) & + \\
\hline $\mathrm{MKTINFO}_{8}$ & $\begin{array}{l}\text { access to market information services (price trends, buyers, suppliers) } \\
(\text { dummy variable: } 1=\text { Yes, } 0=\text { No) }\end{array}$ & \\
\hline SUPPFINSUR $_{9}$ & $\begin{array}{l}\text { support from financial and insurance services (credit, savings, insurance institutions) } \\
\text { (dummy variable: } 1=\text { Yes, } 0=\text { No) }\end{array}$ & + \\
\hline SUPPTNSTOR $_{10}$ & $\begin{array}{l}\text { support from transport and storage services (e.g. grain purchasing, haulage) } \\
\text { (dummy variable: } 1=\text { Yes, } 0=\text { No) }\end{array}$ & + \\
\hline SUPPTEXT $_{11}$ & $\begin{array}{l}\text { support in the form of training and extension (technical and business training) } \\
\text { (dummy variable: } 1=\text { Yes, } 0=\text { No) }\end{array}$ & + \\
\hline SUPPQASUR $_{12}$ & $\begin{array}{l}\text { support from quality assurance providers (research, innovation, development monitoring) } \\
\text { (dummy variable: } 1=\text { Yes, } 0=\text { No) }\end{array}$ & + \\
\hline TECHIMPQ $_{13}$ & adopted technology for improved production quality (dummy variable: $1=$ Yes, $0=$ No) & + \\
\hline TECHIMPKG $_{14}$ & adopted technology for improved packaging (dummy variable: $1=$ Yes, $0=$ No) & + \\
\hline TECHEFF $_{15}$ & adopted technology for efficient production (dummy variable: $1=$ Yes, $0=$ No) & + \\
\hline TECHSAFE $_{16}$ & $\begin{array}{l}\text { adopted technology for improved safety in production (as regards health and safety stand- } \\
\text { ards) (dummy variable: } 1=\text { Yes, } 0=\text { No) }\end{array}$ & + \\
\hline
\end{tabular}

Source: own elaboration. 
the past year? This is a good indicator since some entrepreneurs also measured their success based on how they perceived the growth of their business. The above was merged into one question based on the replies. The result was ultimately used as a proxy for the dependent variable, with the predictors being grouped into two categories (socio-demographic characteristics and environmental factors). The variables are as defined below.

The function is specified as:

$$
S U C C=\beta_{0}+\beta_{1 \ldots 16}+\mu
$$

where:

$S U C C=$ entrepreneurial business success (binary outcome: Yes $=1, \mathrm{No}=0$ )

$\beta_{1}-\beta_{16}$ are the coefficients of the independent variables which are to be determined and are defined below.

\section{RESULTS AND DISCUSSION}

Demographic characteristics of entrepreneurs Female-owned enterprises prevailed in the group of businesses surveyed (with a share of nearly $70 \%$ ). These were mainly restaurants and food vendors from the informal sector, generally owned and operated by females in the Ghanaian setting (Table 2). The age of entrepreneurs surveyed ranged between 17 and 67 years. A large part of them (56\%) had no formal education while about $23 \%$ were educated up to the junior high school level. In terms of business experience, more than half (53\%) of entrepreneurs had been engaged in their businesses for more than 10 years (Fig. 2) and only about $2 \%$ were very new in the business environment, having spent less than one year as entrepreneurs. The above implies that a large proportion of entrepreneurs in this survey had more years of business experience. This could be a good indicator of success since they would have had enough time to implement adequate strategies to meet their goals.

The respondents cited different reasons for having started their current businesses (Table 3). One of the replies was a precedent set in their families. Such entrepreneurs felt the need to start up their business because of the success chalked by family members who had previously engaged in such businesses. Other motivating factors for starting businesses were monetary gain; putting into practice the knowledge acquired in school; easy access to raw materials; passion for this type of
Table 2. Demographic characteristics of entrepreneurs

\begin{tabular}{lrc}
\hline \multicolumn{1}{c}{ Category } & Frequency & Percent (\%) \\
\hline Gender & & \\
Male & 915 & 31.5 \\
Female & 1988 & 68.5 \\
Total & 2899 & 100.0 \\
Age distribution & & \\
Less than 18 years & 8 & 0.3 \\
18-35 years & 791 & 27.5 \\
36-60 years & 1778 & 61.8 \\
Above 60 years & 300 & 10.4 \\
Total & 2877 & 100.0 \\
Highest educational qualification & & \\
None & 1597 & 56.0 \\
Primary & 375 & 13.1 \\
Junior High School/Middle & 642 & 22.5 \\
School Leaving Certificate & & \\
Senior High School/Vocational/ & 148 & 5.2 \\
Technical school & & 0.5 \\
Diploma & 57 & 2.0 \\
Degree & 19 & 0.7 \\
Postgraduate & 2 & 0.1 \\
Other (specify) & & \\
Total & & \\
\hline & & \\
& & \\
\hline
\end{tabular}

Source: own elaboration based on survey data.

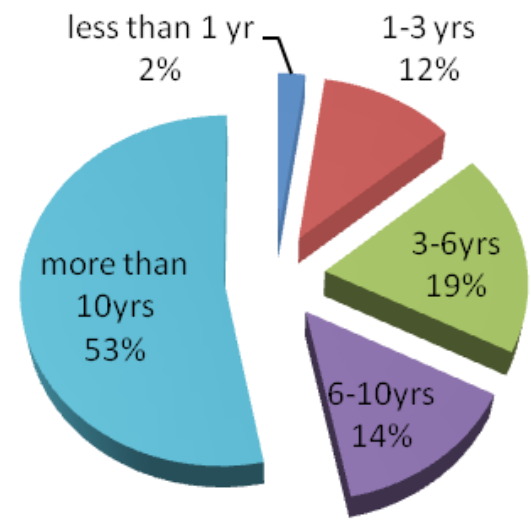

Fig. 2. Number of years of business experience of entrepreneurs Source: own elaboration based on survey data. 
Table 3. Motivation for starting a business by current business success status (\%)

\begin{tabular}{lcc}
\hline \multicolumn{1}{c}{ Motivational reason } & $\begin{array}{c}\text { Successful } \\
\text { businesses }\end{array}$ & $\begin{array}{c}\text { Unsuccessful } \\
\text { businesses }\end{array}$ \\
\hline Family business as motivation for starting a business & 18.3 & 17.4 \\
Monetary gain as motivation for starting a business & 34.8 & 36.3 \\
Professional training as motivation for starting a business & 0.6 & 0.6 \\
Source of employment as motivation for starting a business & 34.9 & 37.2 \\
Easy access to raw materials as motivation for starting a business & 4.2 & 4.0 \\
Passion as motivation for starting a business & 4.9 & 2.7 \\
High product demand as motivation for starting a business & 2.3 & 1.8 \\
Total & 100.0 & 100.0 \\
\hline
\end{tabular}

Source: own elaboration based on survey data.

business; and the trend of high demand observed in that business in the local economy. Among both successful and unsuccessful businesses, monetary gain and source of employment were the most frequently cited main incentives for starting a business.

\section{Relationship between socio-demographic features, motivation for starting a business and business success: the chi-squared test} The significance test was based on the fact that if the calculated chi-squared score is equal to or greater than the critical value, the $p$-value is at or below the preset level $(p=0.05)$. Therefore, the null hypothesis may be rejected. Conversely, if the calculated chi-squared score is below the critical value, it implies that the p-value is above the preset level, and the null hypothesis cannot be rejected. The chi-squared test resulted in a score of 4.532 for the age of entrepreneurs and 12.439 for the education level, both of which are greater than the critical value of 3.524 (at $p=0.05$ ). Therefore, the null

Table 4. $\mathrm{Chi}^{2}$ significance test for business success and sociodemographic factors of entrepreneurs

\begin{tabular}{lrc}
\hline & \multicolumn{1}{c}{$X^{2}$} & Asymp. sig. (2-sided) \\
\hline Age of entrepreneur & 4.532 & 0.209 \\
Education level & 12.439 & 0.087 \\
Business experience & 3.273 & 0.513 \\
\hline
\end{tabular}

Source: own elaboration based on survey data. hypothesis is rejected because the results suggest a significant relationship between the age and education level of entrepreneurs and their business success (Table 4). However, the chi-squared value of 3.273 calculated for the entrepreneurs' business experience is below the critical level of 3.524. Therefore, the null hypothesis cannot be rejected because the results show no significant relationship between business experience and business success.

There is no significant relationship between business success and continuity in family (heritage) business as a motivation to commence (Table 5). The study does not reject the hypothesis on the absence of significant

Table 5. $\mathrm{Chi}^{2}$ significance test between business success and motivational factors for starting a business

\begin{tabular}{lcc}
\hline \multicolumn{1}{c}{ Motivating factors } & Value & $\begin{array}{c}\text { Asymp. sig. } \\
(2 \text {-sided })\end{array}$ \\
\hline Continuity in family business & 5.041 & 0.080 \\
Monetary gain & 1.262 & 0.532 \\
$\begin{array}{l}\text { Professional training in a type } \\
\text { of business }\end{array}$ & 0.025 & 0.874 \\
Source of employment & 0.660 & 0.416 \\
Easy access to raw materials & 0.096 & 0.757 \\
Passion for business & 41.767 & 0.000 \\
High product demand & 2.875 & 0.090 \\
\hline
\end{tabular}

Source: own elaboration based on survey data. 
relationships between monetary gain, professional training in the business, easy access to raw materials, the business as a source of employment and high product demand as motivating factors for entrepreneurs in engaging in their businesses, on one side, and their business success, on the other.

\section{The effect of socio-demographic} characteristics and environmental factors on business success

As shown by the results of the binary logit regression, the age and experience of the entrepreneurs do not significantly affect their business success. This is inconsistent with the results from previous research (e.g. Raman, 2004) which found experience to have a critical contribution to business success. The number of years in formal education has a positive significant effect on the chances of business success of entrepreneurs. However, in order to discover the real effect of the period of formal education (a continuous variable) on business success, the proportionate (percentage) change ${ }^{1}$ in the odds of business success in relation to failure was calculated. The result indicates that the tendency to succeed increases by about $67 \%$ with an additional year of education attained by an entrepreneur or, conversely, the odds of business failure decrease by about $33 \%$ if the entrepreneur's education period is extended by one year. This highlights the importance of formal education for business success. The environmental factors are split into two groups: political and macroeconomic factors. Political factors are those linked to the support provided by public institutions (as policy initiatives) to help entrepreneurs engage in a successful private business. The results indicate that the odds of success for agribusiness entrepreneurs increase by 0.17 times if additional training support is provided by the Council for Scientific and Industrial Research (CSIR), a public institution primarily focused on research into technological improvement. The result is even more interesting if GRATIS (another public institution) is involved. An additional support provided by GRATIS will tend to increase the chances of success for agribusiness entrepreneurs by as much as 3.28 times compared to the odds of failure. This result is plausibly explained by the fact that GRATIS focuses its support measures on MSEs active in the processing

${ }^{1}$ display $\left(\exp \left(\_b[E D U C] * 100\right)-\exp \left(\_b[E D U C] * 111\right)\right) /$ $\exp (\mathrm{b}[\mathrm{EDUC}] * 111) * 100=-66.921165$
Table 6. Factors of success in the agribusiness

\begin{tabular}{llll}
\hline & Odds ratio & \multicolumn{1}{c}{$p>z$} & Std. err. \\
\hline AGE & 1.001743 & 0.752 & .00551 \\
EDUC & 1.105802 & $0.038^{* *}$ & .0535579 \\
EXP & 0.979993 & 0.233 & .0166161 \\
CSIR & 0.1560007 & $0.000^{* * *}$ & .0606608 \\
BAC & 1.518867 & $0.081^{*}$ & .3641734 \\
GRATIS & 3.284717 & $0.002^{* * *}$ & 1.241307 \\
SUPPINPUTSS & 1.92024 & $0.000^{* * *}$ & .2916178 \\
MKTINFO & 2.269982 & $0.000^{* * *}$ & .3467733 \\
SUPPFINSUR & 1.052632 & 0.779 & .1920972 \\
SUPPTNSTOR & 1.543631 & $0.053^{*}$ & .3460108 \\
SUPPTEXT & 0.6768174 & $0.010^{* *}$ & .1025897 \\
SUPPQASUR & 1.607846 & 0.261 & .6793998 \\
TECHIMPQ & 0.583665 & $0.000^{* * *}$ & .0760698 \\
TECHIMPKG & 0.7029919 & $0.047 * *$ & .1246004 \\
TECHEFF & 0.4236404 & $0.000^{* * *}$ & .0699954 \\
TECHSAFE & 0.568932 & $0.001 * * *$ & .0935164 \\
Cons & 0.3788208 & $0.003 * * *$ & .1242403 \\
\hline
\end{tabular}

$* * * p<0.01, * * p<0.05, * p<0.1$.

Dependent variable (binary outcome): Success $=1$, Failure $=0$ Source: own elaboration based on survey data.

industry, and tremendously contributes to their success. A very important macroeconomic factor, access to market information, exerted a positive effect on business success. This was manifested by the fact that the odds for entrepreneurial business success increased by 2.27 times if the entrepreneurs had access to market information regarding their products.

\section{SUMMARY AND RECOMMENDATIONS}

This study intended to identify the socio-demographic characteristics of micro and small agribusiness entrepreneurs, and to determine the effect they have (together with some selected environmental factors) on business success. Based on relevant literature, the null hypothesis on the absence of a significant relationship between age and education level of entrepreneurs (on one side) and business success (on the other) is rejected 
since the results proved otherwise. However, no significant relationship exists between the number of years of business experience and business success. Also, this study reveals that supportive environmental factors (especially public institutional support) contribute to the success of agribusiness entrepreneurs in Ghana. Access to the ready market and market information (prices, trends, buyers, etc.) are factors with significant effect on business success. Because of the importance of institutional support and accessible market information to business success, policy intervention must be geared towards strengthening these areas to increase the rate of business success of agribusiness entrepreneurs. What also needs to be noted is that their success has a positive ripple effect on the whole Ghanaian economy due to the downstream and upstream linkages in the agribusiness sector.

\section{REFERENCES}

Aryeetey, E., Baah-Nuakoh, A., Duggleby, T., Hettige, H., Steel, W. F. (1994). Supply and Demand for Finance of Small Scale Enterprises in Ghana, Discussion Paper No. 251, World Bank, Washington, DC. pp. 1-16. elibrary. worldbank.org/doi/pdf/10.1596/0-8213-2964-2

Chowdhury, M. S., Alam, Z., Arif, Md. I. (2013). Success Factors of Entrepreneurs of Small and Medium Sized Enterprises: Evidence from Bangladesh. Bus. Econ. Res., 3(2), 1-15. http://dx.doi.org/10.5296/ber.v3i2.4127

Hayford, S. (2012). The Development of Small Medium Enterprises and their impact to the Ghanaian Economy. A MBA thesis submitted to the Institute of Distance Learning, KNUST, Ghana. Retrieved from: ir.knust.edu.gh/handle/ $123456789 / 4837$

Hisrich, R. D. (1990). Entrepreneurship/intrapreneurship. Am. Psych., 45(2), 209-222. http://dx.doi.org/10.1037/ 0003-066X.45.2.209

Kayanula, D., Quartey, P. (2000). The Policy Environment for Promoting Small and Medium. Sized enterprise in Ghana and Malawi, Finance and Development Research Programme Working Paper Series no. 15.
Larsen, P., Lewis, A. (2007). How award-winning SMEs manage the barriers to innovation. Creat. Innov. Manag., 16(2), 142-151. http://dx.doi.org/10.1111/j.1467-8691.2007. 00428.x

Luk, T. (1996). Success in Hong Kong: Factors self-reported by successful small business owners. J. Small Bus. Manag., 34(3), 68-78.

Lussiers, R. N., Pfeifer, S. (2001). A crossnational prediction model for business success. Int. J. Small Bus. Manag., 39(3), 228-239. http://dx.doi.org/10.1111/0447-2778.00021

McDowell, S. D. (1997). Globalization, Liberalization and Policy Change: A Political Economy of India's Communication Sector. New York: St. Martin Press. http://dx.doi. org/10.1057/9780230374638

Mead, D., Liedholm, C. (1998). The dynamics of micro and small enterprises in developing. countries. J. World Dev., 26(1), 61-74. http://dx.doi.org/10.1016/ S0305-750X(97)10010-9

Mintoo, A. A. (2006). SMEs in Bangladesh. CACCI J. 1(1), 1-19. http://www.techmonitor.net/tm/images/6/66/04sep_ oct_sf6.pdf

Nimoh, F., Tham-Agyekum, E. K., Aduamah, E. O. (2011). Factors Influencing the Performance of Entrepreneurs in the Kumasi Metropolis of Ghana. Int. J. Pure Appl. Sci. Technol., 3(2), 128-140.

Perez, E., Canino, R. (2009). The importance of Entrepreneur's perception of success. Rev. Int. Comp. Manag., 10(5), 990-1010.

Raman, R. (2004). Motivating factor of educated self-employed in Kerala: A case study of Mulanthuruthy Block Ernakulum. Discussion Paper No. 90. Kerala Research Programme on Local Development Center for Development Studies.

Villars, J. (2004). Speech Delivered at a Workshop of the Ghana Investment Advisory Council, Akosombo, 5 June, 2004.

Wanigasekara, W. M. S. K., Surangi, H. K. N. S. (2010). Impact of Level of Education and Business Experience and Business Success among Small Retail Owner Managers in SriLanka. Retrieved 29 Jan 2016 from: http://www.kln. ac.lk/fcms/ICBI2011/images/ICBM/dccs/Microsoft $\% 20$ Word $\% 20 \% 20 \mathrm{P} 01 . p d f$ 